\title{
O CUIDADO DE SI: ATRAVESSAMENTOS NA EDUCAÇÃO
}

\author{
Marcelo Vicentin ${ }^{1}$
}

\section{Introdução}

Michel Foucault ao dirigir seus olhos para a Antiguidade grega e romana procurou compreender como se constituíram como sujeitos; como diferentes escolas (platônicos, epicuristas, estoicos, cínicos entre outros) problematizaram a formação de um cuidado de si (epiméleia heatoû, para os gregos; cura sui, para romanos), um ocupar-se de si, de preocuparse consigo a fim de se constituírem sujeitos, por meio técnicas e práticas que visavam um conhecer-se na transformaçãode suas próprias experiências e na relação com os outros. Para tanto, um necessário cuidado de si, em que o aprendizado, o conhecimento sobre sifoi uma entre inúmeras atividades, práticas, exercícios de inquietude existencial, de uma forma de vida.

O gnôthi seautón ('conhece-te a ti mesmo') aparece, de maneira bastante clara e [...] no quadro geral da epiméleia heautoû (cuidado de si mesmo), como uma das formas, umas das consequências, uma espécie de aplicação concreta, precisa e particular, da regra geral: é preciso que te ocupes contigo mesmo, que não te esqueças de ti mesmo, que tenhas cuidados contigo mesmo. É nesse âmbito, como que no limite desse cuidado, que aparece e se formula a regra 'conhece-te a ti mesmo' (FOUCAULT, 2010, p. 6).

No entanto, a episteme moderna reordenou as relações entre conhecer-se a si e cuidar de si. Estedeixou de ser um preceito, uma atividade, uma ocupação, um trabalho de/sobre a vida, valorizado, passando a significar, negativamente, uma relação egoística, o abandono a obrigações com os outros, com a cidade, com a nação. Em contrapartida, o "conhece a timesmo", via procedimento cartesiano, transfigurou-se no retorno a uma origem, uma essência, uma verdade primeira e fundante sobre a existência humana como forma de consciência, único acesso à verdade; circunstância que nos distanciou de nós mesmos, de nosso centro, submetendonos a outros eixos de poder.

Para tanto, desse conhecimento de si cartesiano, emergiram movimentos que implicaram no que somos, fazemos e pensamos, como vivemos; modelos de conhecimento e racionalidade atuantes na produção de sentidos universais, de saberes que nos libertam de certa menoridade;a produção de um próprio entendimento de si mesmo, a fim de alcançar certa maioridade, com implicações espirituais, institucionais, éticas e políticas: a tarefa de se inventar como sujeito autônomo, um modo de ser histórico e, como enfatiza Foucault (2008b, p. 345), "um êthos filosófico que seria possível caracterizar como crítica permanente de nosso ser histórico".

Desses movimentos, uma das máquinas foi a escola moderna, a escola republicana, entrelaçando educação e democracia, direitos citadinos para a expansãodos ideais de igualdade, justiça e liberdade, mediante um saber externo, capaz produzir uma consciência livre, emancipada, de pensar por si própria, sem o auxílio de razão alheia;pelo exercício da cidadania, a edição de leis, a liberdade civil. René Schérer (2009) identificou na escola republicanaa emergência de uma maquinaria para adaptar o cidadão ao Estado. Uma maquinaria de disciplina e normalização, de produção de condutas, de táticas de governamentalidade.

\footnotetext{
1 Pós-doutorando pela Universidade São Francisco, Itatiba, São Paulo. Bolsista Capes. E-mail: marcelovicentin@yahoo.com.br.
} 
[...] por 'governamentalidade', entendo a tendência, a linha de força que, em todo o Ocidente, não cessou de conduzir, e há muitíssimo tempo, em direção à preeminência desse tipo de saber que se pode chamar de 'governo' sobre todos os outros: soberania, disciplina. Isto, por um lado, levou ao desenvolvimento de toda uma série de aparelhos específicos de governo e, por outro, ao desenvolvimento de toda uma série de saberes. (FOUCAULT, 2015, p. 296- 297)

Essa governamentalidade, para Foucault (2010), ao se colocar como centro de irradiação de condutas, de condução e governamento dos outros, como representação de poder político e suas instituições, se articulou na constituição do sujeito de direitos. Todavia, nos adverte que em seu sentido mais amplo, governamentalidade não remete apenas ao político, mas à mobilidade e reversibilidade das relações de poder. Deste modo, governamentalidade, como modelo de resistência ao instituído, deve considerar uma relação de si para consigo, "considerar que relações de poder/governamentalidade/governo de si e dos outros/ relação de si para consigo compõem uma cadeia, uma trama e que é em torno destas noções que se pode articular a questão da política e a questão da ética" (FOUCAULT, 2010, p. 225).

Dentro desta trama, desta cadeia de governamentalidade, a maquinaria escolar tem papel fundamental pela proposição de um conhecimento externo que conduz de certa minoridade à maioridade, e na constituição de um sujeito de diretos; logo, espaço de reversibilidade, de mobilidade na condução dos sujeitos, de formas de resistência a um tipo de subjetividade que busca anular, fazer esquecer a possibilidade de modelarmos por nós mesmos nossa conduta ética e política.

\section{Cuidado de si}

Com A hermenêutica do sujeito, conforme Fredéric Gros (2008, 2011), Foucault reorientou a rota de suas pesquisas sobre o poder com a incorporação do tema do cuidado de si a partir do momento helenístico-romano: um sujeito ativo sobre si mesmos, constituindo-se por meio de práticas regradas, e não mais um sujeito passivo, constituído mediante à técnicas de poder-saber.

O sujeito suposto por essas técnicas de si, pelas artes da existência é um eu ético, antes que um sujeito ideal de conhecimento. Isto significa que o sujeito é compreendido como transformável, modificável: é um sujeito que se constrói, que se dá regras de existência e conduta, que se forma através dos exercícios, das práticas, das técnicas, etc. [...]O que significa dizer que a "subjetividade"[...] não remete evidentemente nem a uma substância nem a uma determinação transcendental, mas a uma reflexividade que se poderia chamar de prática: uma maneira de se relacionar consigo mesmo para se construir, para se elaborar.(GROS, 2008, p. 127-128)

Os diálogos entre Sócrates e Alcebíades, em O banquete, utilizados por Foucault (2011) em A hermenêutica do sujeito, indicam a presença da epimeléia heautoû na cultura helênica, uma tradição, um preceito, uma atividade, um dever e técnica de vida que, naquele momento, embaralhava o tema do cuidado de si com o tema do conhecimento de si; Essas relações, tradição de modos de subjetivação, perpassaram o platonismo, o epicurismo, o estoicismo, o cristianismo, com suas nuances e oposições, possibilitando, conforme Foucault $(2011,2014)$, três modelos distintos: o platônico e o cristão, correntes mais expressivas, e o helenísticoromano, encoberto, marginalizado pelos outros modelos. 
$\mathrm{Na}$ escola platônica, exemplificada em $O$ banquete, a relação com a política, a pedagogia e o conhecimento de si. Alcebíades quer governar a cidade, mas não é capaz de governar-se. Sócrates - a quem o deus confio sua tarefa de zelar pelos seus concidadãos a se preocuparem a cuidar deles próprios, a ocuparem-se de si mesmos a fim de se ocuparem da própria cidade interpela Alcebíades, sobre suas pretensões sobre a cidade e seus concidadãos, a fim de afirmar a ignorância deste sobre si próprio, fruto de uma má pedagogia; logo, a necessidade de cuidarse e, para tanto, conhecer-se, para poder governar-se e governar aos outros e a cidade.

Nesse movimento de retorno a si, o conhecimento de si se torna ocupação única e principal, via reminiscência, lembranças para que se possa acessar a verdade presente na alma. "O movimento pelo qual a alma se volta para si mesma é um movimento pelo qual seu olhar é atraído para "o alto" - para o elemento divino, para as essências e para o mundo supraceleste no qual essas são visíveis" (FOUCAULT, 2014, p. 181).

$\mathrm{Na}$ escola cristã, no século subsequente, em paralelo ao modelo platônico, o conhecimento de si associado à purificação do corpo, para a compreensão de uma verdade, também externa, presente nos textos bíblicos. Para alcançar esta verdade se faz necessário ocupar-nos de nós mesmos a fim de reconhecer e dissipar ilusões, seduções e tentações que nos cercam e nos impedem de ter acesso à verdade. Entretanto, contrário à reminiscência platônica, no modelo exegético cristão, o conhecimento de si não busca um retorno ao ser da alma, mas detectar a natureza e a origem dos clamores da alma. Nessa preocupação consigo, a renúncia sobre si próprio para viver a verdadeira vida após a morte.

Diferentemente, e entre, à reminiscência platônica e à exegese cristã, o movimento das escolas epicuristas, cínica e, principalmente, estoica, denominadas por Foucault (2011), de a era de ouro e o ápice do cuidado de si, caracterizam-se pela valorização da constituição do eu como objetivo primordial para uma autofinalização da relação a si, da conversão a si, mediante práticas morais austeras. Concentrar-se sobre si próprio é acompanhar, investir em nossas capacidades e faltas, pelo esforço de atividades que nos tornam mais fortes e corajosos para práticas e exercícios sobre a natureza das coisas e um completo domínio de si.

Essas relações de si para si próprio não se orientam na constituição de um egoísmo ou alienação do mundo, pois se estabelecem sempre na relação com um outro que auxilia nos cuidados para conosco e nos trabalhos de si para consigo, bem como sempre estar em comunicação com outrem, o que desfaz a possibilidade de ser uma atividade solitária, visto o estabelecimento de práticas e atividades com alguém, um mestre ou alguém mais velho: cartas, conversações, ensinamentos, formações etc., a fim de vigiar e intensificar a presença consigo, durante toda a vida, da infância a velhice.

Esse tempo não é vazio: ele é povoado por exercícios, por tarefas práticas,
atividades diversas. Ocupar-se de si não é uma sinecura. Existem os cuidados com
o corpo, os regimes de saúde, os exercícios físicos sem excesso, a satisfação, tão
medida quanto possível, das necessidades. Existem as meditações, as leituras, as
anotações que se toma sobre livros ou conversações ouvidas, e que mais tarde
serão relidas, a rememoração das verdades que já se sabe mas que convém
apropriar-se ainda melhor. (FOUCAULT, 2013, p. 56- 57)

Por conseguinte, pelo não esvaziamento no individualismo, uma relação política, relações entre o sujeito e as coisas e o mundo que o cerca, relações que requerem certo distanciamento para que, ao invés de uma reação e precipitação espontânea, haja a devida contemplação para uma ação condizente ao problema e ao sujeito. De acordo com Gros (2008, p. 132): "não se trata de renunciar ao mundo e aos outros, mas de modular de outro modo esta relação com os outros pelo cuidado de si". 


\section{Pedagogia e cuidado de si.}

Foucault (2011) escreveu que o cuidado de si transbordou a finalidade de um conhecimento de si, tornando-se uma atividade coexistente a vida. Nessa transformação do cuidado de si platônico para o praticado, principalmente, pelos estoicos, está a pedagogia. $\mathrm{Na}$ perspectiva socrático-platônica, a pedagogia falhava na formação dos jovens, ao não os preparar adequadamente para um verdadeiro ingresso na vida, da adolescência à vida adulta, colocandoos em situação de ignorância perante a si e aos outros. De tal modo, o cuidado de si, via conhecimento de si, se impunha a fim de completar ou substituir a formação recebida.

Em contrapartida, nos epicuristas e estoicos, o ocupar-se de si percorre toda a extensão da vida, e, portanto, o vínculo entre uma aprendizagem que visa a um conhecimento definido e específico de algo para um momento singular da vida, vai diluindo-se; substitui-se por uma instrução que prepare para a vida, para a existência, para ocupar-se consigo e sua vida. Práticas que não visam apenas ao preparo para o ingresso nas decisões da cidade, mas a complexidade da uma vida plena.

Por conseguinte, da diluição da ação pedagógica ateniense, emergem outras práticas, como: o combate permanente consigo mesmo, por toda a vida, ao invés da constituição de um homem para uma ação futura; uma terapêutica, com maior ênfase ao modelo médico que ao pedagógico, a fim de tratar das paixões, desejos, dos males da alma; a crítica, de caráter formador e corretivo de si, dos outros, do mundo, de desaprender as más e/ou desnecessárias aprendizagens.

Na prática de si que vemos desenvolver-se no decurso do período helenístico e romano, ao contrário, há um lado formador que é essencialmente vinculado à preparação do indivíduo, preparação porém não para determinada forma de profissão ou de atividade social: não se trata, como no Alcebíades, de formar o indivíduo para tornar-se um bom governante; trata-se independentemente de qualquer especificação profissional, de formá-lo para que possa suportar, como convém, todos os eventuais acidentes, todos os infortúnios possíveis, todas as desgraças e todos os revés que possam atingi-lo. Trata-se, consequentemente, de montar um mecanismo de segurança, não de inculcar um saber técnico e profissional ligado a determinado tipo de atividade. [...] A instructio é essa armadura do indivíduo em face dos acontecimentos e não a formação em função de um fim profissional determinado. (FOUCAULT, 2010, p. 85-86)

Uma vez que a ação pedagógica deixou de ser um imperativo para uma finalidade específica, condicionadora ou formadora para fins militares ou políticos, assumindo a forma de princípio geral e incondicionado, o cuidado de si se tornou uma regra coextensiva à vida, correspondendo a um modo de perceber-se e estar no mundo, de agir e de relacionar-se com os outros. Dessa forma, o cuidado de si alcançou uma abrangência comunitária e institucional, constituindo-se em uma rede de relações sociais, praticável por todos, sem nenhuma condição prévia de status ou finalidade técnica, profissional, social; para governar os outros. Como afirma Gros (2008, p. 131), "o que interessa a Foucault neste cuidado de si é a maneira como ele se integra num tecido social e constitui um motor da ação política". Uma construção ética que se sobrepõe a uma ação individualista, de uma fuga para si próprio, preconizando um sujeito de ação sobre o mundo que o cerca, pela correspondência entre os atos e as palavras.

Instruir para os acontecimentos da vida soa muito diferente ao processo de emancipação da escola moderna e republicana, de condução de uma minoridade a uma maioridade, que nos parece, cada vez mais sob a lógica neoliberal, preocupada com a quantificação de resultados, de tarefas e atividade pela divisão de saberes, pela secção do humano, e isoladas, que se 
descreve e estuda. Salma Tantos Muchail (2011) escreve que a presença do discurso de uma ética acoplada com o cuidado de si implica na incapacidade do projeto educacional da modernidade em dar conta de suas metas, de transpor a minoridade de crianças e jovens para a maioridade, uma tecnologia de poder tal, que Rancière (apud GALLO, 2013, p. 3) denomina "embrutecimento, o exato oposto de emancipação".

Gallo (2002) ao propor uma educação menor, busca modos de subversão perante o processo escolar implantado pela modernidade, de conduzir a certa maioridade; busca o embate com o triunfo de uma sociedade pedagogizada pela modernidade. Educação como ato de revolta e resistência ao imposto pelas políticas educacionais de controle e disciplina. Para tanto, assentado em Gilles Deleuze e Félix Guattari, propõe a desterritorialização dos processos educativos; a ramificação política, em que toda educação é um ato político; o valor coletivo, com a educação nunca acontecendo como um ato isolado. Três características que se aproximam e se apropriam do cuidado de si proposto por Foucault (2011), permitindo sugestionar:

a reciprocidade de uma ação ética baseada num cuidado de si e num cuidado do outro, em que o jogo da construção da liberdade só pode ser jogado como um jogo coletivo, de mútuas interações e relações, em que as ações de uns implicam em ações de outros. Um jogo em que uns se fazem livres aprendendo da liberdade dos outros; em que uns se fazem livres na medida em que ensinam a liberdade aos outros (GALLO, 2006, p. 188).

Como Foucault (2011), que não defende o cuidado de si como um modelo a ser implantado e seguido, constituindo-se naquele que prepondera, o modelo a ser seguido, Gallo (2013), propõe não um modelo de educação, mas outras formas de pensar a escola por linhas de fuga na relação com a variante dominante, por uma invenção cotidiana do fazer pedagógico, que se distancie da reprodução de padrões.

\section{Palavras finais}

Como observado por Foucault, o cuidado de si não deve ser tomado como um modelo a sobrepor outro modelo, ele apenas propõe o conhecimento, a leitura de princípios que constituíram, em determinado momento, relações extensivas do imperador ao escravo; modos de se relacionar com o mundo e com o outros que produziram um sujeito ético, ao invés de um sujeito moral, como o sujeito da modernidade. Ao permitir-se ao discurso de uma educação sob os auspícios do cuidado de si, convida-se a ser sujeito de suas ações, a implicar-se com atos e palavras, a experimentar a condução de si próprio e a dividir com outrem, provocando uma relação política pela importunação à certa governamentalidade, visto que a presença de uma instrução que estimule o cuidado de si diverge do processo de condução apenas pelo político instituído.

Aos que possam pensar na implosão do modelo escolar, o que se propõe não é a implantação de outros modelos, a obrigatoriedade de um modelo ou outro, mas a polissemia de uma educação menor atravessada pelo cuidado de si, por meio de conhecimentos que Foucault (2011) denomina de ethopoéticos, que orientam e transformam o modo de ser e as condutas do sujeitos envolvidos;contrariamente a um uso instrumental e ornamental do conhecimento que, por finalidade, não afeta nem transforma o sujeito; ou o divide, secciona em partes observáveis - sujeito que observa e objeto observado, natureza e humano. Por conseguinte, a distinção pelo modo, uso do conhecimento e não seu conteúdo.

De tal modo, uma escola atravessada por currículos, práticas, atividades que não observem apenas territórios instituídos, mas que trafegue entre fronteiras modeláveis ao sabor 
de ventos produzidos de jogos de liberdade recíprocos, mediante às técnicas próprias ao cuidado de si, ocupando, transmutando os espaços, os dispositivos.

Esses ventos são produzidos nos textos que compõem a última parte deste dossiê, produzindo o embate, a partir das fronteiras, com um discurso já instituído, problematizando os modos de governamento, contra-argumentando a partir do cuidado de si.

Deste modo, o texto de Alan Isaac Mendes Caballero e Antonio Carlos Dias Junior coloca no embate as práticas de gestão escolar, doravante a responsabilidade pelo cuidado do outro, pelas lentes da questão de gênero. Navegando por $O$ cuidado de si, a gestão escolar e o armário como problema nas relações de gênero, problematizam os atravessamentos entre educação e questões sexuais, para proporem o cruzamento da pedagogia queer, a metáfora do ciborgue e o cuidado de si como prática pedagógica a fim de uma educação em que o gênero aparece como experimentação (pessoal e compartilhada) e autoconhecimento.

O embate sobre a governamentalidade no dispositivo pedagógico prossegue em Entre a sujeição e a subjetivação: reflexões sobre as práticas curriculares em 'escolas quilombolas', de Evanilson Tavares de França e Jackeline Rodrigues Mendes, que problematizam as distâncias, os caminhos a serem percorridos entre a cultura dos quilombolas e os currículos oficiais. Entre sujeição e subjetivação, as práticas escolares, se alimentadas pelo cuidado de si, podem possibilitar que o sujeito olhe para si mesmo, para ao cuidado de si mesmo; logo, conduzindo-o ao cuidado do outro.

No texto de encerramento deste dossiê, Ana del Valle Duarte Castillo e Elizabeth Gomez Souza, também ocupam o mundo escolar para problematizar a formação do professor de Matemática. As autoras de Cuidado de si: un até de reflexión en el desarrollo profesional del docente de matemática, argumentam a favor de exercícios e práticas do cuidado de si, de exame de consciência, contribuindo no processo pedagógico do ensino da matemática.

Distante de um modelo, ou de modos de total condução e obediência, seja do mestre, da moral, da governamentalidade, subentende uma escolha pessoal, em que emerge o usufruir de modificar-se a si pelas suas próprias ações, por meio de uma educação que produza experiências de si, de exercícios, atividades, práticas de condução de si e do outro, que questionem nossos limites, problematizando nossas escolhas e decisões, o que fazemos de nossa vida, nosso modo de existir. Por consequência, a invenção outros modos de existência pela problematização da própria existência, nunca pronta, dada, definida; a percepção de que a história não se constitui reta, linear, lisa, mas cheia de sobressaltos, desvios, caminhos alternativos no existir humano.

\section{Referências}

FOUCAULT, M. O que são as luzes? In: MOTTA. M. B. (Org.). Ditos e escritos, volume II: arqueologia das ciências e história dos sistemas de pensamento. Tradução de E. Monteiro. 2. ed. Rio de Janeiro: Forense Universitária, 2008. p. 333-351.

FOUCAULT, M. A hermenêutica do sujeito. Tradução de M. A. Fonseca e S. T Muchail. 3. ed. 2. reimp. São Paulo: WMF Martins Fontes, 2011.

FOUCAULT, M. História da sexualidade 3: o cuidado de si. Tradução de M. T. C. Albuquerque. 12. ed. Rio de Janeiro: Graal, 2013.

FOUCAULT, M. A hermenêutica do sujeito. In: MOTTA, M. B. (Org.). Ditos e escritos, volume IX: genealogia da ética, subjetividade e sexualidade. Tradução de A. Chiquieri. Rio de Janeiro: Forense Universitária, 2014. p. 177-191. 
FOUCAULT, M. A governamentalidade. In: MOTTA, M. B. (Org.). Ditos e escritos, volume $I V$ : estratégia, poder-saber. Tradução de V. L. A. Ribeiro. 3. ed. 2. reimp. Rio de Janeiro: Forense Universitária, 2015. p. 275-298.

GALLO, S. Em torno de uma educação menor. Educação e Realidade. v. 27, n. 2, jul.-dez. 2002. p. 169-178. Disponível em: 〈https://seer.ufrgs.br/educacaoerealidade/article/view/25926>. Acesso em: 01 de dez. 2018.

GALLO, S. Cuidar de si e cuidar do outro. In: KOHAN, W. O.; GONDRA, J. (Org.). Foucault 80 anos. Belo Horizonte: Autêntica, 2006. p. 177-190.

GALLO, S. Em torno de uma educação menor: variáveis e variações. $36^{\text {a }}$ REUNIÃO NACIONAL DA ANPED, GT 13, de 29 de setembro a 02 de outubro de 2013, Goiânia-GO. Disponível em: <http://36reuniao.anped.org.br/pdfs_trabalhos_encomendados/gt13 trabencomendado_silviogallo.p df $>$. Acesso em: 01 de dez. 2018.

GROS, F. O cuidado de si em Michel Foucault. In: RAGO, M.; VEIGA-NETO, A. (Org.). Figuras de Foucault. Tradução de M. Rago; A. Veiga-Neto. 2. ed. Belo Horizonte: Autêntica, 2008. p. 127-138.

GROS, F. Situação do curso. In: A hermenêutica do sujeito. FOUCAULT, M. Tradução de M. A. Fonseca; S. T Muchail. 3. ed. 2. reimp. São Paulo: WMF Martins Fontes, 2011.

MUCHAIL, S. T. Foucault: mestre do cuidado. São Paulo, Loyola, 2011.

SCHÉRER, R. A utopia pedagógica. In: SCHÉRER, R. Infantis: Charles Fourier e a infância para além das crianças. Tradução de G. J. F. Teixeira. Belo Horizonte: Autêntica, 2009. p. 25-40. 